\title{
Effect of Water Spray in Controlling Temperature of Hot Gas Propagation through Double Skin Facade
}

\author{
Wolter Purba $^{1 *}$, Afiri Dianti ${ }^{1}$, Jefri Sigalingging ${ }^{1}$, Nadhira Gilang Ratnasari ${ }^{1}$ and Yulianto Nugroho ${ }^{1}$ \\ ${ }^{1}$ Department of Mechanical Engineering, Faculty of Engineering, Universitas Indonesia, Kampus UI Depok 16424, Indonesia
}

\begin{abstract}
The rapid development of science and technology have contributed in the applied building design. One of them is the improvement of the construction design of the building envelope. Current high-rise building design impacts in wider building envelop surface area and greater heat load received from the sun irradiation. One of the common used design is the doubleskin façade type building envelope. The insulation characteristic given by the envelope interlayer gap can reduce the heat load received. However, in fire cases, the gap becomes hot gasses path, supporting wider flame propagation. Its position in the outside leads to harder fire suppression effort. During this time, the active fire protection system design has just considering fire scenarios inside the building. This research is conducted to see water droplets impact as extinguisher aspect on interlayer gap hot gasses propagation. The experiment used wooden layer with $540 \mathrm{~mm}$ x $80 \mathrm{~mm}$ x $6 \mathrm{~mm}$ dimention as the envelope layer. The interlayer gap varies among others $30 \mathrm{~mm}, 50 \mathrm{~mm}$, and $70 \mathrm{~mm}$ to see flame output characteristic through and time needed for 4 nozzles to extinguish the flame. The suppression system applied is expected to be a solution in the case of double-skin façade building envelope fire event.
\end{abstract}

\section{Introduction}

Population growth along with the technology development contribute in high-rise building demand in developed countries. Apart from the residences, high-rise building functions such as office space and shopping centre. The higher the building, the wider the surface area of the building envelope is, thus the higher heat load from the sun received. The higher heat load causes greater energy demand in high-rise building. The development of science and technology contributes in applied building design to promote feasible energy efficiency. It relates to the energy usage management and advancement of the material used in the building. One of the methods is to reduce the sun heat load through the outer surface material of the building. The insulation material (façade) usage in the envelope will prevent the heat wave from the sun to enter the building [1].

The benefits of façade wall usage is promoting energy efficiency, ease of the material installation, and light material load [2]. Indirectly, the façade wall usage saves. Despite of the energy efficiency benefit, the usage of façade wall has an impact on the higher fire risk. In façade wall fire cases, the fire propagates rapidly and results in thick smokes [3]. Innovation is carried out in preventing fire propagation on sheath materials. A lot of façade basic components are being producted from inflammable material to reduce the fire propagating effect on the façade surface. Nevertheless, it costs higher than other material which causing low attractiveness for building contractor to use façade material. Some researchs have found that the effect of horizontal projection installation in sheath material [4]. The addition of that barrier material affects the propagation characteristic of the flame comes out from the façade gaps.

In high-rise building fire case, the double-skin façade usage will be the first option for the building envelope. The insulation properties given by the façade interlayer gap can lessen the sun-heat load received. However, the gaps between façade materials become a pathway for hot gasses to propagate [5]. Even though façade design is developed continuously, high-rise building fire case is still at high risk. The position of the facade material in the outer area complicates the extinguishing process. Until now, the design of an active fire protection system only taken into account the fire scenario occurs within the building. Therefore, the internal system of the building cannot minimize the heat load due to flame or the hot gas that propagates in the facade material including the gap in between. Based on this background, the fire test experiment is conducted on various gap cases between material and inter-material wetting effect.

\footnotetext{
Corresponding author: yulianto.nugroho@ui.ac.id
} 
This experiment is expected to induce the innovation on suppression system installation in the gaps between façade to reduce the fire propagation.

\section{Experimental}

Fig. 1 shows the set-up experiment scheme that consists of burning zone and wetting zone. The wall of chamber of burning zone use fire resistant material, i.e. kalsiboard. The experiment is designed to cover various gap distance with opening of $\mathrm{W} / \mathrm{H}=2(200 \mathrm{~mm} \times 100$ $\mathrm{mm})$ and $\mathrm{W} / \mathrm{H}=0.5(100 \mathrm{~mm} \times 200 \mathrm{~mm})$. The 4 nozzles that used in the experiment have flow rate \pm 0.0039 liters/s for each one and placed above the burning material in the interlayer gaps. The material used as a sheath wall is a wood-based board with a thickness of $0.6 \mathrm{~mm}$. The source of the fire is a wooden stick, with mass of $160-170$ grams, which is placed at the floor of the combustion chamber, and ignited by fire. The water impact experiment on the propagating hot gas is done build upon the test time. 120s after the fire was turned on, the external cladding is applied and for wetting experiment, extinguish system started together.

In those periods, the flame has reached its maximum temperature on vertical point $(\mathrm{z})$. Before the extinguish method is ran, the vertically propagating flame analysis was conducted. With the similar experiment set, the flame characteristic that went through the inter-layer gaps could be seen. In general, vertical flame experiment was conducted in big scale experiment. This was caused by the flame base position clearance and flame to material phenomenon [6-8]. Indeed, in this experiment, the set-up was designed in small scale to see the water droplets impact to the flame. With total material height of $80 \mathrm{~cm}$, it is expected to be able to describe the thorough phenomenon on various inter-layer gaps. The fire suppression system is being activated until the wooden stick, as fuel, is extinguished. When the hot gas could not be pushed out to the outside in $60 \mathrm{~s}$, the data sampling is over.

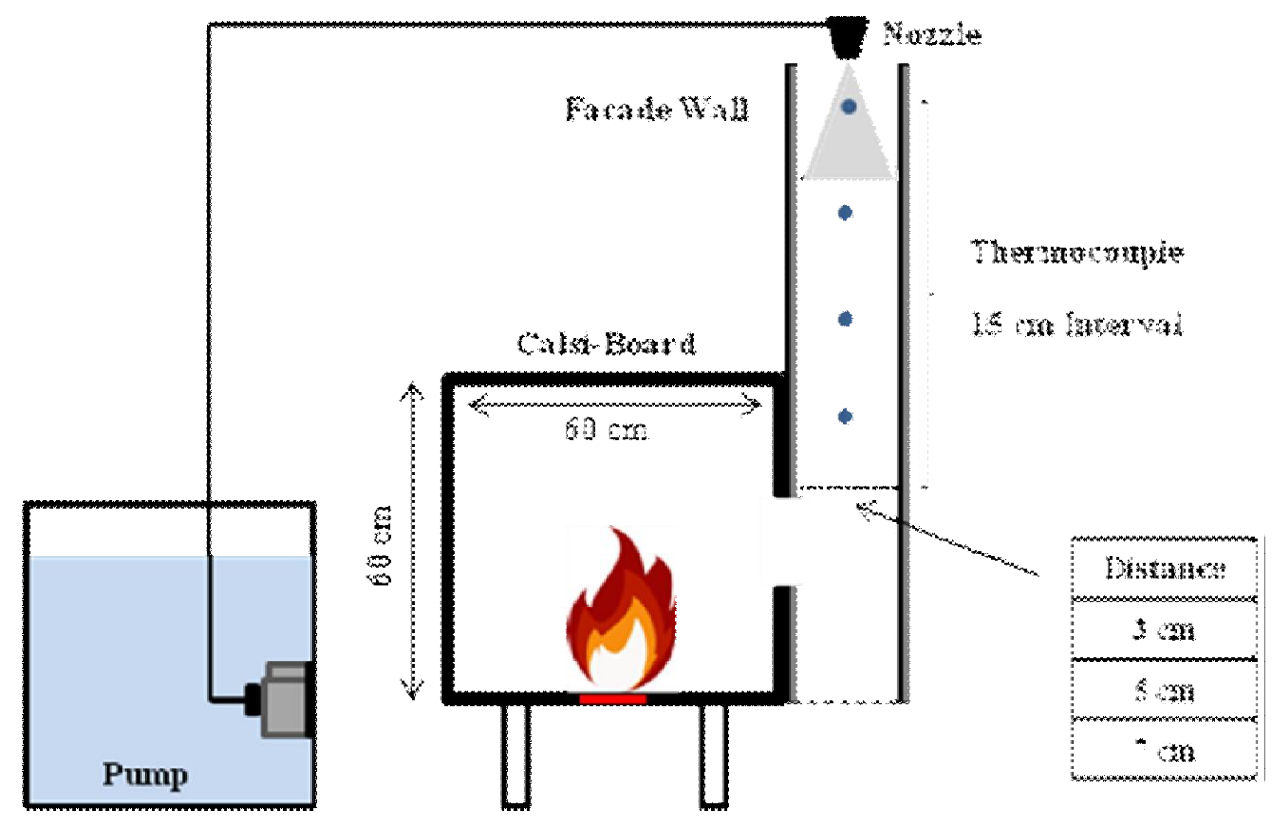

Fig. 1. Set up experiment scheme

\section{Results and discussion}

The wetting experiment on inter-layer gaps is aimed to see the characteristic of vertical hot gas propagation in the building envelope with varying the gaps distance and effective extinguish system. Fig. 2 shows the temperature distribution due to the hot gas existing through the openings with dimensions of $200 \mathrm{~mm} \times 100$ $\mathrm{mm}(\mathrm{W} / \mathrm{H}=2)$. The external sheath was applied at a distance of $3 \mathrm{~cm}, 5 \mathrm{~cm}$, and $7 \mathrm{~cm}$ after $120 \mathrm{~s}$ of combustion.
It appears that there is maximum difference in temperature, which is $220^{\circ} \mathrm{C}$ for a distance of $3 \mathrm{~cm}$, $150^{\circ} \mathrm{C}$ for a distance of $5 \mathrm{~cm}$, and $200^{\circ} \mathrm{C}$ for a distance of $7 \mathrm{~cm}$. The maximum temperature is measured at a distance of $15 \mathrm{~cm}$ from the top edge of the opening to wooden board. The maximum temperature occurs in the $200 \mathrm{~s}$ at a distance of $5 \mathrm{~cm}$ and $7 \mathrm{~cm}$, while for a distance of $3 \mathrm{~cm}$, the maximum temperature occurs at $400 \mathrm{~s}$. 


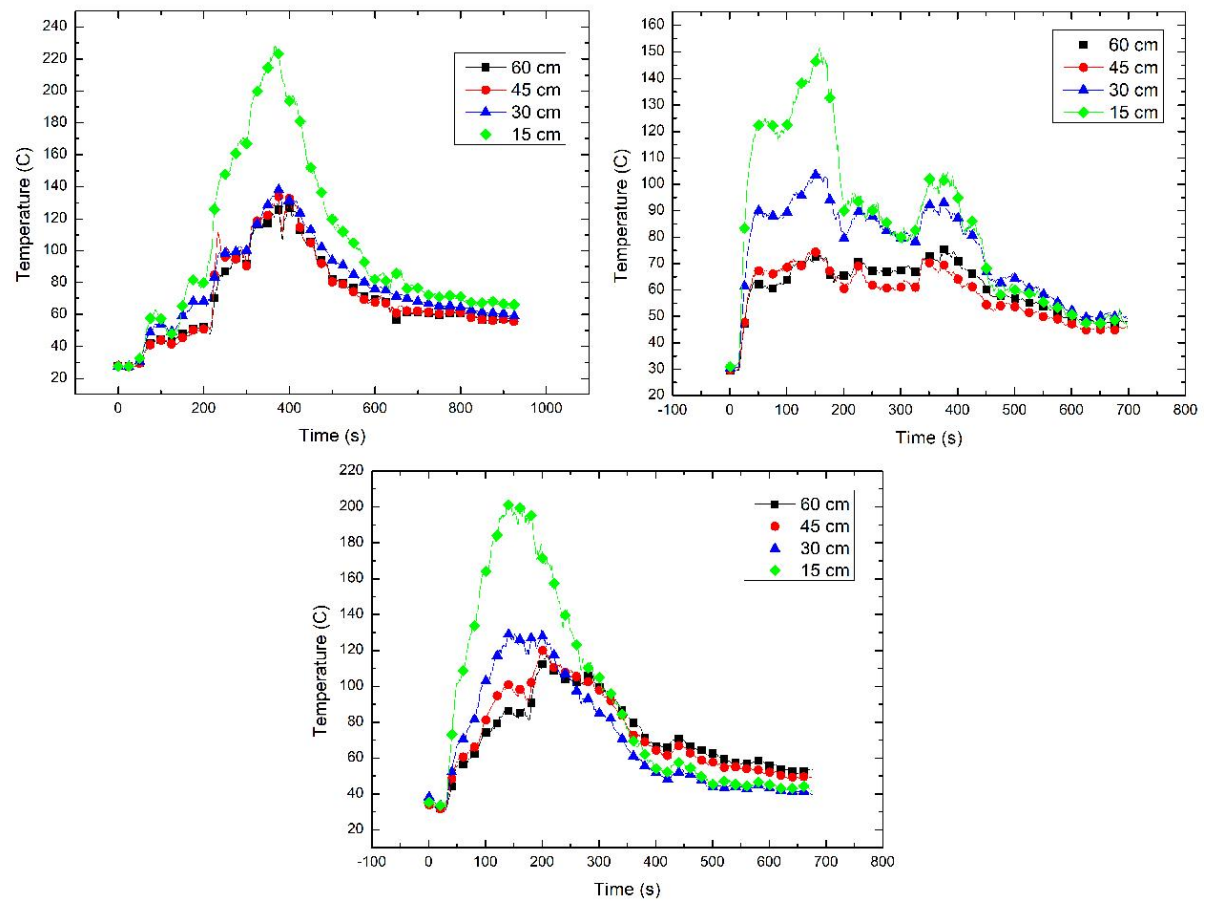

Fig. 2. Temperature measurement for openings $200 \mathrm{~mm} \times 100 \mathrm{~mm}$ at distance $3 \mathrm{~cm}, 5 \mathrm{~cm}$, and $7 \mathrm{~cm}$

This shows the distance between the gaps affecting the air distribution through the opening. A very small gap makes the air entering through the opening is not as big as other gaps. This phenomenon affects the rate of combustion of wood as fuel becomes slower. For hot gas distribution, the pattern illustrated by using infra red cameras in Fig. 3 shows similarities in each experiment. At $<120$ s, the wood-burning hot gas will fill the combustion chamber first. The hot gas will fill the layer

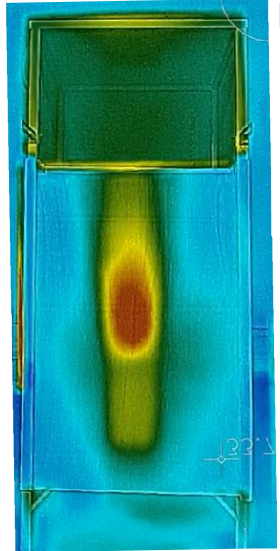

220 s

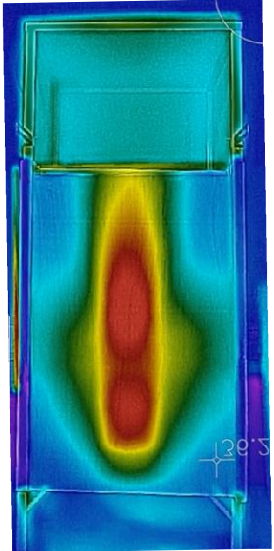

420 s

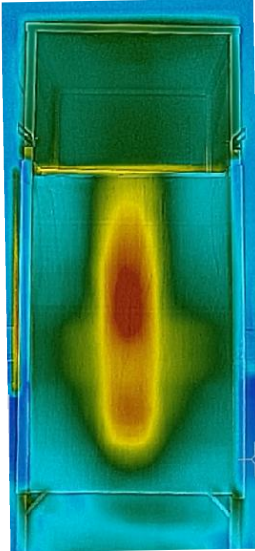

$710 \mathrm{~s}$

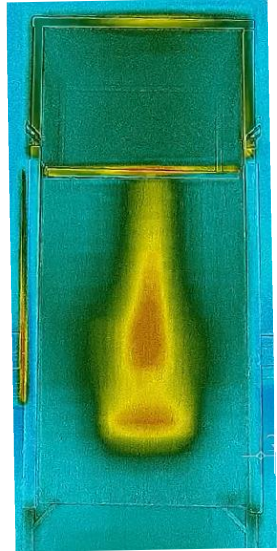

220 s

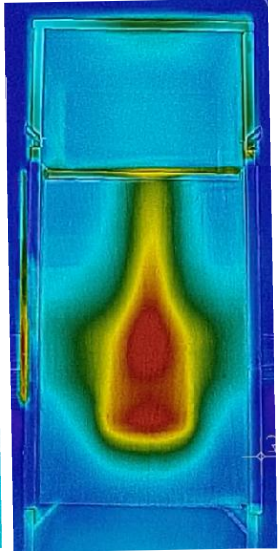

$590 \mathrm{~s}$

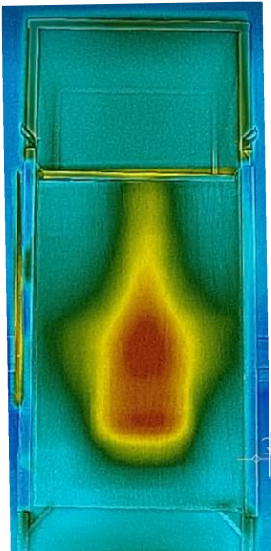

$1000 \mathrm{~s}$ (a)

Fig. 3. Infrared photography for openings $100 \mathrm{~mm} \times 200 \mathrm{~mm}$ (a) and $200 \mathrm{~mm} \times 100 \mathrm{~mm}$ (b) at distance $5 \mathrm{~cm}$ 

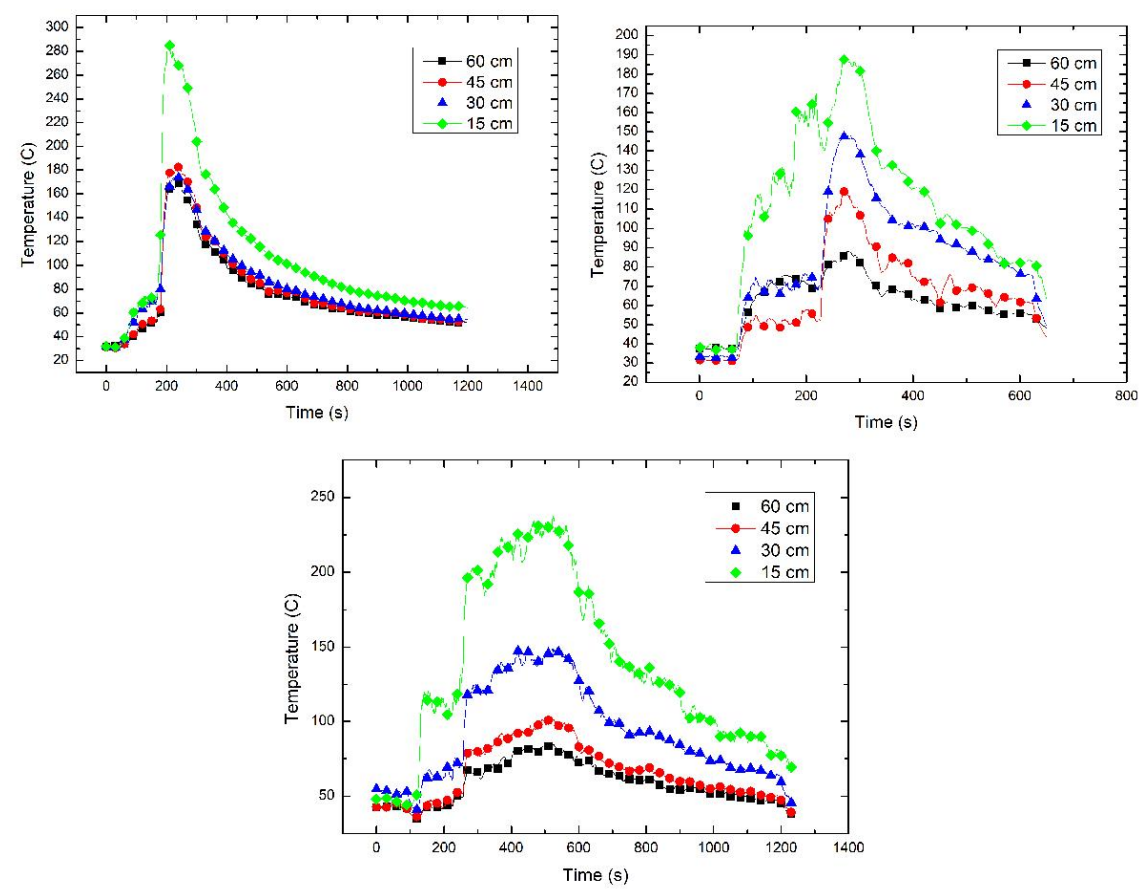

Fig. 4. Temperature measurement for openings $100 \times 200 \mathrm{~mm}$ at distance $3 \mathrm{~cm}, 5 \mathrm{~cm}$, and $7 \mathrm{~cm}$

Seen from Fig. 4, the maximum measured temperature at the opening with dimension $100 \mathrm{~mm} \mathrm{x}$ $200 \mathrm{~mm}$ indicates a difference in the time required. At the opening of this $\mathrm{W} / \mathrm{H}=0.5$, the maximum temperature for a distance of $3 \mathrm{~cm}$ is $290^{\circ} \mathrm{C}, 190^{\circ} \mathrm{C}$ for a distance of $5 \mathrm{~cm}$, and $230^{\circ} \mathrm{C}$ for a distance of $7 \mathrm{~cm}$. In addition, the time required to reach the maximum temperature is different, where, for a distance of $3 \mathrm{~cm}$ needs $200 \mathrm{~s}$, distance of $5 \mathrm{~cm}$ needs $280 \mathrm{~s}$ and distance of $7 \mathrm{~cm}$ needs $600 \mathrm{~s}$. The hot gas pattern that exits through the opening ratio of 0.5 is different from the 2.0 ratio

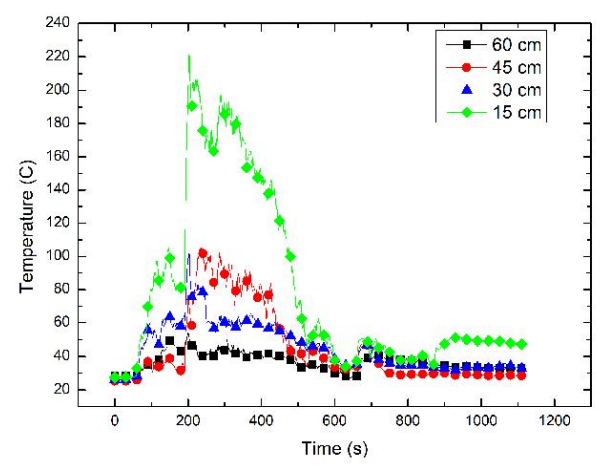

was showed. The open dimension affects the hot gas distribution that exits from opening to reach the outer wall. In the experimental openings $\mathrm{W} / \mathrm{H}=0.5$, water spray applications were also applied at each wooden board distance. Fig. 5 shows that the effect of water on temperature distribution by hot gas propagation. Application of water spray done $120 \mathrm{~s}$ after combustion. This application coincides with the installation of the outer sheath. Water spray affects the flow of hot gas out through the openings.

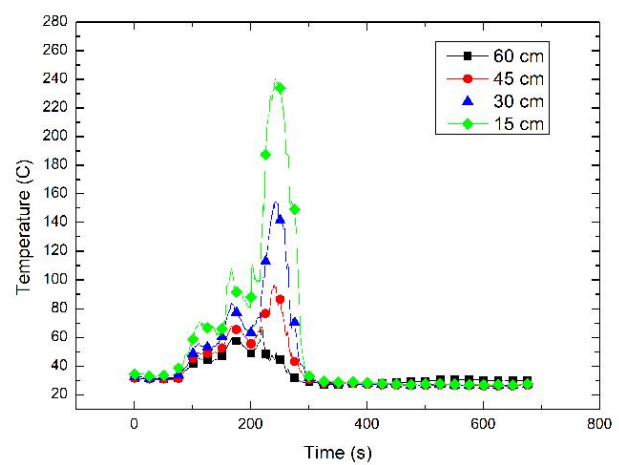

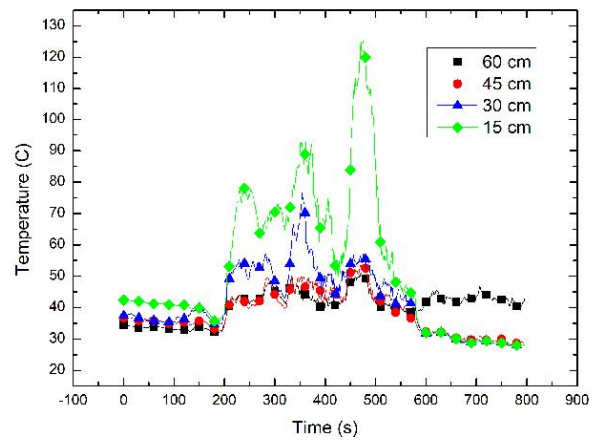

Fig. 5. Temperature measurement for openings $100 \times 200 \mathrm{~mm}$ at distance $3 \mathrm{~cm}, 5 \mathrm{~cm}$, and $7 \mathrm{~cm}$ with water spray 


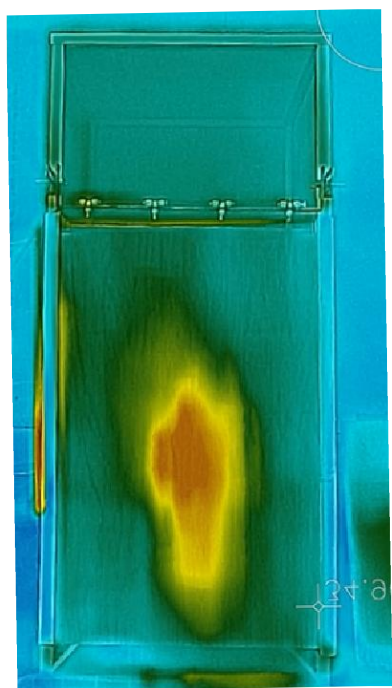

200 s

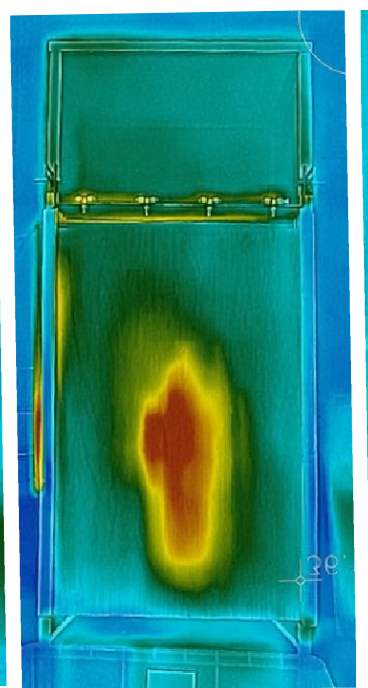

$280 \mathrm{~s}$

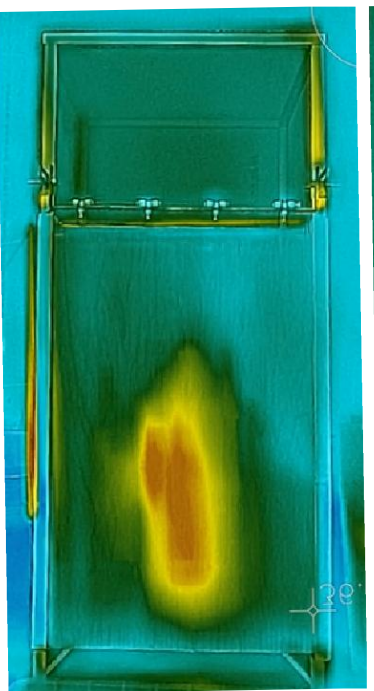

$440 s$

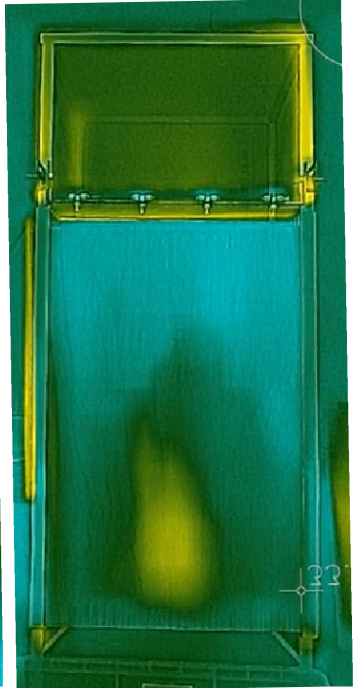

$600 \mathrm{~s}$

Fig. 6. Infrared photography for openings $100 \times 200 \mathrm{~mm}$

Temperature distribution in Fig 6 indicates that water succeeds in blocking hot gas flowing upward at a distance of $3 \mathrm{~cm}$ and $5 \mathrm{~cm}$. The effect of wetting by the water spray between the gaps is also shown by Fig 6 . Unlike $7 \mathrm{~cm}$ distance, the temperature fluctuates due to the uneven distribution of water, when compared to other distances. Range of temperatures in this distance is lower than others. However, this phenomenon shows that the larger the gap of the sheath, the greater the need for water to block the flow of hot gas. The total volume of water required is 4.563 liters for a distance of $3 \mathrm{~cm}$, 4.259 liters for a distance of $5 \mathrm{~cm}$, and 5.780 liters.

\section{Conclusions}

Through the abovementioned series of experiments, it can be found that there is influence of the distance between gaps to the hot gas distribution ejected out through the openings. Dimensions of the opening affect the characteristics of hot gas, since it correlates with the ratio of the opening $(\mathrm{W} / \mathrm{H})$. In addition, the gaps between boards affect the value of the temperature in the gap. Almost all experiments show that the small gap, which $3 \mathrm{~cm}$, has the highest temperature rate. The method of spraying water on the gap provides alternative in controlling temperature in double skin facade. Based on experimental data, water spray can reduce the heat from hot gas that spread through the gap, especially for 3 $\mathrm{cm}$. However, this water spraying method is deemed less effective for gap distance $\geq 7 \mathrm{~cm}$. The hot gas flows between the large gaps makes the effect of water on hot gas less effective, resulting in high water demand.

The authors would like to thank Unversitas Indonesia for the financial support through the PITTA 2018 funding scheme with a contract number 2566/UN2.R3.1/HKP.05.00/2018.

\section{References}

1. Chow, W. and J. Liu, Fire Hazards of Façade Materials for Energy Conservation under Flashover. Energy Procedia, 78: p. 3483-3488 (2015)

2. Nguyen, K.T., et al., Performance of modern building façades in fire: a comprehensive review. Electronic Journal of Structural Engineering, 16: p. 1 (2016)

3. Guillaume, E., et al., Study of fire behaviour of facade mock-ups equipped with aluminium composite material-based claddings, using intermediate-scale test method. Fire and Materials (2018)

4. Fu, J., Y. Li, and J. Zhang, Effects of the Horizontal Projection on the Distribution of the Façade Temperature (2015)

5. Chow, L.C., Spread of smoke and heat along narrow air cavity in double-skin façade fires. Thermal Science, 18(suppl. 2): p. 405-416 (2014)

6. $\mathrm{Hu}, \mathrm{L}$., et al., Window ejected flame width and depth evolution along facade from under-ventilated enclosure fires. Fire Safety Journal, 76: p. 44-53 (2015)

7. Lu, K., et al., Facade flame heights from enclosure fires with side walls at the opening. Procedia Engineering, 62: p. 202-210 (2013)

8. Lu, K., et al., Heat flux profile upon building facade with side walls due to window ejected fire plume: An experimental investigation and global correlation. Fire Safety Journal, 70: p. 14-22 (2014) 